\title{
Optimisation and Validation of a High Throughput Screening Compatible Assay to Identify Inhibitors of the Plasma Membrane Calcium ATPase Pump - a Novel Therapeutic Target for Contraception and Malaria
}

\author{
Tamer M A Mohamed ${ }^{1,2}$, Simon A Zakeri ${ }^{1}$, Florence Baudoin ${ }^{1}$, Markus Wolf ${ }^{3}$, Delvac Oceandy ${ }^{1}$, Elizabeth J \\ Cartwright $^{1}$, Sheraz Gul $^{3}$, Ludwig Neyses ${ }^{1}$ \\ ${ }^{1}$ Institute of Cardiovascular Sciences, Manchester Academic Health Sciences Centre, University of Manchester, \\ Manchester M13 9PT, UK. ${ }^{2}$ Dept. of Biochemistry, Faculty of Pharmacy, Zagazig University, Zagazig, Egypt. \\ ${ }^{3}$ European ScreeningPort GmbH, 22525 Hamburg, Germany.
}

Received, March 13, 2013; Revised, April 25, 2013; Accepted, May $8^{\text {th }}, 2013$; Published, May $10^{\text {th }}, 2013$.

\begin{abstract}
Purpose. ATPases, which constitute a major category of ion transporters in the human body, have a variety of significant biological and pathological roles. However, the lack of high throughput assays for ATPases has significantly limited drug discovery in this area. We have recently found that the genetic deletion of the ATP dependent calcium pump PMCA4 (plasma membrane calcium/calmodulin dependent ATPase, isoform 4) results in infertility in male mice due to a selective defect in sperm motility. In addition, recent discoveries in humans have indicated that a single nucleotide polymorphism (SNP) in the PMCA4 gene determines the susceptibility towards malaria plasmodium infection. Therefore, there is an urgent need to develop specific PMCA4 inhibitors. In the current study, we aim to optimise and validate a high throughput screening compatible assay using recombinantly expressed PMCA4 and the HTRF ${ }^{\circledR}$ Transcreener ${ }^{\circledR}$ ADP (TR-FRET) assay to screen a drug library. Methods and Results. PMCA4 membrane microsomes were prepared from HEK293 cells overexpressing PMCA4. Western blot quantification revealed nearly nine-fold increased expression of PMCA4 compared to LacZ (control virus)-infected cells. Maximal PMCA4 microsomal activity was achieved in the TR-FRET assay with $15 \mathrm{ng} / \mu 1$ microsomal concentration, 30-minute pre-incubation with compounds at $37^{\circ} \mathrm{C}$, and calcium buffering with $1 \mathrm{mM}$ EGTA providing $1 \mu \mathrm{M}$ free-calcium. Finally a dose-response curve for carboxyeosin (a non-specific PMCA inhibitor) under optimised conditions showed significant PMCA4 inhibition. Upon confirmation that the assay was suitable for high-throughput screening, we have screened the ChemBioNet small molecule library ( 21,000 compounds) against the PMCA4 assay to identify those that are its apparent inhibitors. This screening yielded 1,494 primary hits. Conclusions. We have optimised the HTRF ${ }^{\circledR}$ Transcreener $^{\circledR}$ ADP assay for high-throughput screening to identify PMCA4 inhibitors. The output of the screening campaign has provided preliminary chemical starting points that could be further developed to specific PMCA4 inhibitors for non-hormonal contraception or anti-malaria therapy.
\end{abstract}

This article is open to POST-PUBLICATION REVIEW. Registered readers (see "For Readers") may comment by clicking on ABSTRACT on the issue's contents page.

\section{INTRODUCTION}

P-type ATPases are a group of protein which utilise the energy generated from adenosine triphosphate (ATP) hydrolysis predominantly to facilitate the movement of cations, $\mathrm{Na}^{+}, \mathrm{K}^{+}, \mathrm{H}^{+}$or $\mathrm{Ca}^{2+}$ against the concentration gradient. In the human body, examples include the sodiumpotassium pump $\left(\mathrm{Na}^{+} / \mathrm{K}^{+}\right.$-ATPase), the proton pump $\left(\mathrm{H}^{+} / \mathrm{K}^{+} \quad\right.$ ATPase $)$, sarco-endoplasmic reticulum calcium ATPase (SERCA), and the plasma membrane calcium/calmodulin dependent ATPase (PMCA). The $\mathrm{Na}^{+} / \mathrm{K}^{+}$-ATPase pump, which is ubiquitously expressed, facilitates cell ionic gradients, ionic transport, and in both neurones and muscle cells it maintains cell resting potential by extruding three sodium ions from the cell in exchange for two potassium ions. The activity of this enzyme energizes such diverse functions as the maintenance of the membrane potential and the renal and intestinal handling of solutes [1-3]. The gastric $\mathrm{H}^{+} / \mathrm{K}^{+}$-ATPase exploits a very similar enzymatic mechanism to catalyze the exchange of intracellular protons for

\footnotetext{
Corresponding Author: Ludwig Neyses, Institute of Cardiovascular Sciences, Manchester Academic Health Sciences Centre, University of Manchester. Room 1.302 Stopford Bldg, Oxford Road, Manchester,, United Kingdom; Email. Ludwig.Neyses@manchester.ac.uk
} 
extracellular potassium ions, thus generating the enormous proton gradients associated with gastric acid secretion [4]. SERCA is ubiquitously expressed, and is known to facilitate uptake of calcium into the sarco/endoplasmic reticulum from the cytosol. This is important in cardiac muscle relaxation, in which the sarcoplasmic reticulum is essentially refuelled with calcium for subsequent contraction to take place [5-9]. Finally, the PMCA family, are a group of pumps that extrude calcium from the cytosol into the extracellular space, control calcium homeostasis, and in some cases regulate intracellular signalling pathways. There are four main isoforms: PMCA1, 2, 3 and 4, each one being encoded by a different gene. Every cell contains at least one PMCA isoform, with PMCA activity being driven by the hydrolysis of ATP $[10,11]$.

Recent Genome Wide Association Studies (GWAS) and studies of genetically modified mice have revealed potentially important roles for PMCA isoforms in human disease. A number of the human GWAS have identified single nucleotide polymorphisms (SNPs) in the PMCA1 gene as the single strongest association with blood pressure (BP) variance in humans [12-15]. PMCA2 which is expressed in the cilia of the inner ear, Purkinje cells and the mammary gland, has been implicated in deafness [16-18]. PMCA3 is expressed in brain tissue, pancreatic islet cells, and skeletal muscle, but less is known of the pathophysiological significance [19-21]. However, a recent study in humans has related a single mutation in PMCA3 with ataxia [22]. PMCA4 is by far the most extensively studied isoform. Our own studies in mice lacking PMCA4 [23] revealed that the males were infertile due to a defect in sperm motility, but were otherwise healthy under physiological conditions and had a normal lifespan, as did the females. These findings were confirmed by Okunade et al. who generated a similar PMCA4 knockout mouse model [24]. In addition, a GWAS has shown the PMCA4 gene to be associated with resistance to infection by malaria plasmodium in humans [25]. These findings have collectively implicated PMCAs in a variety of diseases and have led us to optimise and validate a generic PMCA screening compatible assay to be performed for drug discovery purposes. In the current study we used PMCA4 as a model to optimise and validate the HTRF $^{\circledR}$ Transcreener $^{\circledR}$ ADP (TR-FRET) assay for high throughput screening (HTS) of ATPasetargeting compounds. This assay can also be applied to study other ATPases.

\section{METHODS}

\section{Microsome preparation}

HEK293 cells overexpressing PMCA4 or $\beta$ galctosidase (LacZ) were used to prepare PMCA4 and LacZ microsomes as previously described [26]. Briefly, HEK293 cells were cultured and maintained in $175 \mathrm{~cm}^{2}$ flasks, until cells were at $60-70 \%$ confluence. Cells were then infected by 25 Multiplicity Of Infection (MOI) with either recombinant PMCA4 or LacZ adenovirus, for 48 hours. Cells were washed three times with PBS and then harvested in $5 \mathrm{ml}$ harvest solution (1x PBS, $0.26 \% 2 \mathrm{mg} / \mathrm{ml}$ aprotinin, $0.11 \% 2 \mathrm{mg} / \mathrm{ml}$ leupeptin, $0.1 \% 0.1 \mathrm{M}$ PMSF). Harvested cells were centrifuged at $1000 \mathrm{~g}$ for 10 minutes at $4^{\circ} \mathrm{C}$. $3 \mathrm{ml}$ hypotonic solution $(10 \mathrm{mM}$ Tris- $\mathrm{HCl}, \mathrm{pH} 7.5$, $1 \mathrm{mM} \mathrm{MgCl} 2,0.5 \mathrm{mM}$ EGTA, 2mM DTT, $0.2 \%$ $2 \mathrm{mg} / \mathrm{ml}$ aprotinin, and $0.05 \% 2 \mathrm{mg} / \mathrm{ml}$ leupeptin) was added to the cell pellet for 10 minutes on ice. Swelled cells were homogenised in a Dounce homogenizer before addition of $3 \mathrm{ml}$ homogenate solution $(10 \mathrm{mM}$ Tris-HCl, $\mathrm{pH} 7.5,2 \mathrm{mM}$ DTT, $0.38 \mathrm{M}$ sucrose, $0.3 \mathrm{M} \mathrm{KCl}, \quad 0.2 \% \quad 2 \mathrm{mg} / \mathrm{ml}$ aprotinin, and $0.05 \% 2 \mathrm{mg} / \mathrm{ml}$ leupeptin) and homogenization was completed to seal the vesicles. The cell homogenate was centrifuged at $1500 \mathrm{~g}$ for 20 minutes to remove the cellular debris. $60 \mu 10.25 \mathrm{mM}$ EDTA and $1.08 \mathrm{ml}$ of $2.5 \mathrm{M}$ $\mathrm{KCl}$ were added to the supernatant and centrifuged at $100,000 \mathrm{~g}$ for 40 minutes at $4^{\circ} \mathrm{C}$. The resulting pellet was re-suspended in $0.4 \mathrm{ml}$ final solution $(10 \mathrm{mM}$ Tris- $\mathrm{HCl}, \mathrm{pH} 7.5,1 \mathrm{mM}$ DTT, $0.19 \mathrm{M}$ sucrose, $0.15 \mathrm{M} \mathrm{KCl}, 0.2 \% 2 \mathrm{mg} / \mathrm{ml}$ aprotinin, $0.05 \% 2 \mathrm{mg} / \mathrm{ml}$ leupeptin and $0.02 \mathrm{mM}$ $\mathrm{CaCl}_{2}$ ).

\section{Western blotting}

Microsomes overexpressing PMCA4 or $\beta$ galactosidase (LacZ) where lysed with RIPA buffer (1x PBS, 1\% Igepal, $0.5 \%$ sodium deoxycholate, $0.1 \%$ sodium dodecyl sulphate [SDS], $20 \mu \mathrm{M}$ phenylmethylsulfonyl fluoride [PMSF], $500 \mathrm{ng} / \mathrm{ml}$ leupeptin, $1.0 \mu \mathrm{g} / \mathrm{ml}$ aprotinin, and $500 \mathrm{ng} / \mathrm{ml}$ pepstatin). Protein concentrations were determined using a BCA protein assay kit (Pierce). 30 $\mu \mathrm{g}$ of protein extracts were then separated by SDS-polyacrylamide gel electrophoresis and transferred on to a nitrocellulose membrane. Mouse monoclonal antiPMCA4 antibody [JA9] (Abcam) was used for the Western blot analysis and tubulin expression (Abcam) was used as a loading control. The levels of protein expression were quantified using ImageJ software (NIH). 
Homogeneous Time Resolved Fluorescence $\left(\right.$ HTRF $\left.^{\circledR}\right)$ Transcreener ${ }^{\circledR}$ ADP assay

The HTRF $^{\mathbb{B}}$ Transcreener $^{\circledR}$ ADP assay (Cisbio) was used as per manufacturer's instructions with the following modifications. The assay was performed in low volume 384 well black microtitre plates in two steps, namely the enzymatic reaction step followed by a detection step. During the enzymatic reaction, $1 \mu \mathrm{g}$ of PMCA4 microsomes were incubated at $37^{\circ} \mathrm{C}$ in a total volume of $10 \mu 1$ of the optimised reaction mixture containing $50 \mathrm{mM}$ Hepes-Tris $\mathrm{pH} 7.8$, $160 \mathrm{mM} \mathrm{KCl}, 2 \mathrm{mM} \mathrm{MgCl}_{2}, 5 \mathrm{mM} \mathrm{NaN}, 1 \mathrm{mM}$ $\mathrm{CaCl}_{2}, 1 \mathrm{mM}$ EGTA, 1 unit calmodulin, $100 \mu \mathrm{M}$ ATP. For HTRF $^{\circledR}$ Transcreener $^{\circledR}$ ADP assay detection of ATP hydrolysis, $5 \mu 1$ of $\mathrm{Eu}^{3+}$-cryptate antibody and $5 \mu 1$ ADP-d 2 solutions were added and the plate incubated at room temperature for 60 minutes. The HTRF signal from each well was assessed using the FLUOstar Omega Multidetection Microplate Reader, with excitation filter at $337 \mathrm{~nm}$ and using emission filters at $680 \mathrm{~nm}$ and $620 \mathrm{~nm}$ for ADP-d2 and $\mathrm{Eu}^{3+}$-cryptate antibody respectively, the data analysis was performed using Omega software version 1.30 (BMG Labtech). For all wells, F was calculated as the ratio between the $680 \mathrm{~nm}$ reading and $620 \mathrm{~nm}$ reading. The data were presented as ATPase activity $(\%)=\left(1-\left(\mathrm{dF}^{2} \mathrm{dF}_{\max }\right)\right) \times 100 . \mathrm{dF}=\left(\left(\mathrm{F}_{\text {Sample }}\right.\right.$ $\left.\left.-F_{\text {Blank }}\right) /\left(F_{\text {Blank }}\right)\right) \times 100$ and $\mathrm{dF}_{\max }=\mathrm{dF}$ of inactive microsomes which fully inhibited with $25 \mathrm{mM}$ EGTA. The TR-FRET ratio $=$ signal $_{665 \mathrm{~nm}} /$ signal $_{615 \mathrm{~nm}}=$ emmission $_{\mathrm{d} 2 \text { acceptor dye }} /$ emission $_{\mathrm{Eu} 3+-}$ cryptate.

\section{DATA AND STATISTICAL ANALYSIS}

Statistical tests were performed using SPSS. Following a Kolmogorov-Smirnov test normality test, groups were compared using the unpaired student T-test. $\mathrm{P} \leq 0.05$ were considered to be statistically significant.

\section{RESULTS}

HTRF $^{\circledR}$ Transcreener $^{\circledR}$ ADP (TR-FRET) assay The HTRF $^{\circledR}$ Transcreener $^{\circledR}$ ADP (TR-FRET) assay (Cisbio) relies upon the hydrolysis of ATP to ADP. The detection method is based on an antibody specific to ADP which is labelled with $\mathrm{Eu}^{3+}$-cryptate, which is also able to bind to either (d2 acceptor dye)-coupled-ADP (to produce a TR-FRET signal) or ADP released from the enzymatic ATPase reaction (no TR-FRET signal). The resulting TR-FRET signal is inversely proportional to the concentration of the nonlabelled ADP in the sample. As PMCA4 is an ATPase pump that has the ability to convert ATP to ADP with the release of inorganic phosphate (Pi) in a stoichiometric ratio, the released ADP due to ATP hydrolysis by PMCA4 would compete with ADP-d2 and reduce the TR-FRET signal (Figure. 1A). To ascertain that the HTRF assay is suitable to measure the ATPase activity, a standard curve was performed for different ATP:ADP ratios (Table 1). This dose response curve showed a constant increase in the 1$\left(\mathrm{dF} / \mathrm{dF}_{\max }\right)$ values in response to increased ADP/ATP ratios until a plateau phase was reached (Figure. 1B). It was important to use different ADP/ATP ratios for the dose response curve to mimic the ATPase reaction (as ADP is produced, ATP is depleted).

\section{Generation of PMCA4 overexpressing microsomes \\ PMCA4 microsomes were generated from the membranes of HEK293 cells infected with a PMCA4 adenovirus construct. Western blot analysis revealed $\sim 10$ times higher PMCA4 protein expression in the PMCA4-infected cells compared to the LacZ-infected cells $(\mathrm{P}<0.001$; $n=5$ ) (Figure. 2A, B).}

\begin{tabular}{cccc}
\hline \multicolumn{4}{l}{ Table 1. ADP/ATP concentrations for standard curve: } \\
\hline & ADP $(\boldsymbol{\mu M})$ & ATP $(\boldsymbol{\mu M})$ & ATP conversion $\mathbf{( \% )}$ \\
\hline Standard 1 & 0 & 100 & 0 \\
Standard 2 & 0.14 & 99.86 & 0.14 \\
Standard 3 & 0.41 & 99.59 & 0.41 \\
Standard 4 & 1.23 & 98.77 & 1.23 \\
Standard 5 & 3.70 & 96.30 & 3.70 \\
Standard 6 & 11.11 & 88.89 & 11.11 \\
Standard 7 & 33.33 & 66.67 & 33.33 \\
Standard 8 & 100 & 0 & 100 \\
\hline
\end{tabular}




\section{Optimisation of calcium buffering for the PMCA4 microsomes}

Since PMCA4 is a high affinity calcium pump it was important to determine the optimum concentration of freely available calcium ions for maximal PMCA4 microsomal activity, [11]. The calcium dependency of the activity of the PMCA4 microsomal preparation was investigated in the presence of $0.1 \mu \mathrm{M}, 1 \mu \mathrm{M}, 10 \mu \mathrm{M}, 100 \mu \mathrm{M}$, and $1 \mathrm{mM}$ calcium chloride solution, as well as in the absence of external calcium chloride. The ATPase activity was consistently high $(>80 \%$, with a maximum around $90 \%$ ) under all conditions with no inter-variability, suggesting oversaturation of PMCA4 microsomes with free calcium. Even when no calcium was added, the amount of calcium in the final solution where the microsomes were resuspended $\left(20 \mu \mathrm{M} \mathrm{CaCl}_{2}\right)$ was sufficient to activate PMCA4 (Figure. 2C).

By buffering calcium in the presence of $1 \mathrm{mM}$ EGTA, there was a complete inhibition of PMCA4 activity in all $\mathrm{CaCl}_{2}$ concentrations, except in the presence of $1 \mathrm{mM} \mathrm{CaCl}_{2}$ where almost $100 \%$ ATPase activity in the PMCA4 microsomes was observed (Figure. 2D). This suggests that $1 \mathrm{mM}$ EGTA does not fully chelate the calcium and sufficient calcium is available to activate PMCA4. Using an online software tool [27] based on the Fabiato formula [28], we calculated that $1 \mathrm{mM}$ EGTA in the presence of $1 \mathrm{mM} \mathrm{CaCl} 2$ would provide $4 \mu \mathrm{M}$ free calcium under these reaction conditions; which appear to be the optimal for PMCA4 activity to be maximized. At higher concentrations of EGTA $(25 \mathrm{mM})$, essentially all free calcium would be expected to be chelated and thus fully inhibit PMCA4 activity (Figure. 2E), which was confirmed by the fact that $\leq 30 \%$ ATPase activity was achieved across all $\mathrm{CaCl}_{2}$ concentrations. Finally, the inclusion of EDTA at $25 \mathrm{mM}$ indicated that $\leq 20 \%$ ATPase activity remained across all $\mathrm{CaCl}_{2}$ concentrations (Figure. 2F). Therefore, $4 \mu \mathrm{M}$ free calcium as achieved in the presence of $1 \mathrm{mM} \mathrm{EGTA}$ and $1 \mathrm{mM} \mathrm{CaCl}$ solution was verified as the optimum concentration to maximize PMCA4 activity and used in all the following experiments.

\section{Optimisation of the HTRF $^{\circledR}$ Transcreener $^{\circledR}$ ADP (TR-FRET) assay to screen for PMCA4 inhibitors \\ In order to determine the optimal conditions for the $\mathrm{HTRF}^{\circledR}{ }^{\circledR}$ Transcreener ${ }^{\circledR}$ ADP assay to screen for PMCA4 inhibitors, three further experiments were performed (Figures. 3A-C). First, PMCA4}

and LacZ (control) microsomes were tested at a range of different concentrations, up to $25 \mathrm{ng}$ (Figure. 3A). As expected, this experiment revealed minimal background ATPase activity with LacZ across all microsomal concentrations. These results were in contrast to the specific increasing ATPase activity with the PMCA4 microsomes, which reached a plateau between $10 \mathrm{ng} / \mu \mathrm{l}$ and $15 \mathrm{ng} / \mu \mathrm{l}$. Therefore, $15 \mathrm{ng} / \mu \mathrm{l}$ microsomes were used for subsequent experiments. In order to determine the optimum time period for incubation at $37^{\circ} \mathrm{C}$ of PMCA4 microsomal preparations we tested the PMCA4 microsomal activity at different time points, 10, 30 and 60 minutes (Figure. 3B). The PMCA4 activity was significantly higher and appeared to reach a plateau at both 30 and 60 minutes with no significant difference in PMCA4 activity between 30 and 60 minutes $(\mathrm{P}=0.28, n=3)$ across all microsomal concentrations $(10-25 \mathrm{ng} / \mu \mathrm{l}) .30$ minutes was therefore selected as the optimum timing for incubation at $37^{\circ} \mathrm{C}$. In order to confirm that the measured PMCA4 activity could be inhibited, we used the optimised conditions $(15 \mathrm{ng} / \mu \mathrm{l}$ microsome preparation; 30 minutes of incubation period at $37^{\circ} \mathrm{C}$ ), to test the effect of different concentrations of a known non-selective PMCA-inhibitor (carboxyeosin) [29-31] on PMCA4 activity (Figure. 3C). This curve showed a dose response correlation of PMCA4 ATPase activity inhibition by carboxyeosin with an $\mathrm{IC}_{50}$ of $0.5 \mu \mathrm{M}$, reaching almost zero PMCA4 activity at $1 \mu \mathrm{M}$ carboxyeosin concentration. This finding verified that the HTRF $^{\circledR}$ Transcreener ${ }^{\circledR}$ ADP assay has successfully been optimised to screen for PMCA4 inhibitors using the microsomal PMCA4 overexpression system. Furthermore, carboxyeosin was shown to be a suitable positive control inhibitor for use in a screening campaign.

\section{Automating the HTRF $^{\circledR}$ Transcreener $^{\circledR}$ ADP (TR-FRET) assay for high-throughput screening}

The feasibility of automating the assay using a robotic liquid handling system was assessed. The activity of the PMCA4 microsomes was determined in 384 well microtitre plates that were preloaded with 100nl DMSO in each well to determine if any edge effects and/or false positives were detected. Column 24 in each microtitre plate served as a negative control in which $1 \mu \mathrm{M}$ carboxyeosin was used to inhibit PMCA4. The signal was stable up to 4 hours with no significant variation between wells indicating low chances of producing false positives. In 
addition, these results did not show edge effect that is usually apparent in assays that involve incubation at $37^{\circ} \mathrm{C}$ (Figure. $4 \mathrm{~A}-\mathrm{C}$ ). $\mathrm{Z}^{\prime}$ analysis was carried out to measure for the consistency of the readings across the positive and the negative control replicates in the plate $\left(Z^{\prime}=1-((3 \mathrm{x}\right.$ (Standard Deviation of the Maximum Signal Control) $+3 \times$ (Standard Deviation of the Minimum Signal Control) $) /($ (Mean of the Maximum Signal Control) - (Mean of the Minimum Signal Control))) [32]. The Z' analysis showed stability over different timing points which indicated the stability and consistency of the TR-FRET signal over time (Figure. 4D).

\section{Screening of ChemBioNet drug library to identify PMCA4 inhibitors}

To demonstrate that this assay can be used efficiently in a high throughput screening campaign, the PMCA4 assay was evaluated against the ChemBioNet small molecule library ( $\sim 21,000$ compounds) at a concentration of $20 \mu \mathrm{M}$. The TR-FRET assay allows the identification of optically interfering compounds by comparing the $620 \mathrm{~nm}$ signal from the $\mathrm{Eu}^{3+}$ cryptate channel in the presence of compounds with that of the DMSO control populations. Compounds with intensity in $\mathrm{Eu}^{3+}$-cryptate channel $<70 \%$ and $>130 \%$ of DMSO controls were classified as optical interfering compounds (quenching and auto-fluorescent respectively). This screening campaign revealed 1,494 apparent PMCA4 inhibitors when using a $>50 \%$ inhibition cut-off after excluding the optical interfering compounds (Figure. 5).

\section{DISCUSSION}

The present study describes a $\operatorname{HTRF}^{\circledR}$ Transcreener $^{\circledR}$ ADP (TR-FRET) assay that was successfully utilised in a high throughput screening campaign to identify PMCA4 inhibitors. In addition this assay can be modified for other ATPases and it also offers the ability to identify ATPase stimulators. Although there are other ATPase assays that have been optimised for high throughput screening, these rely largely upon undesirable methods to detect ATPase activity [33-35]. Examples include use of radioactive scintillation proximity assay [33] or colorimetric assays [35], as well as coupled-enzyme systems [34] that detect phosphate production linked stoichiometrically to ATP hydrolysis. These assays depend on the hydrolysis of ATP to ADP and inorganic phosphate under the action of PMCA ATPase activity with the resulting inorganic phosphate forming a complex with the malachite green dye to produce a green colour which can be detected [36]. The colorimetric nature of these assays represents an obstacle for use in high or medium throughput screenings as coloured compounds might interfere with the results and produce false positive results. Moreover, compounds that either contain a free phosphate group or one that resembles it would be expected to yield false positive results. Therefore, our proposed TR-FRET assay is a robust and reliable ATPase assay that offers the ability to detect ADP release by ATPases using specific antibodies, thus more accurately and reliably measuring the rate of ATP hydrolysis. Furthermore, the flexibility of the fluorescent readings allows both inhibition and stimulation to be detected, enabling the assay to detect both inhibitors and stimulators of ATPase targets. In addition, our PMCA4 overexpression system using adenovirus resulted in $\sim 10$ fold overexpression of the PMCA4 protein which minimized the interference of the ecto-ATPases already expressed in the microsomes which was confirmed when comparing the PMCA4 microsomes activity against LacZ microsomes. Using the current assay, it was possible to screen the ChemBioNet small molecule library for PMCA4-inhibitors in a single day, which contrasts with the enzyme-coupled assays that would not only take longer but would require suitable counter assays to identify those compounds that are acting upon the enzymecoupled system. The TR-FRET assay also allows the rapid identification of compounds that are either quenchers/autofluorescent which often appear as false positives in fluorescence based screening assays; these can be identified by comparing the signal at $620 \mathrm{~nm}$ from the $\mathrm{Eu}^{3+}$ cryptate channel with the DMSO controls. We chose a generous cut-off of $<70 \%$ and $>130 \%$ for classifying compounds as quenching and autofluorescent respectively; which overcomes the need to perform additional counter assays [37]. This systematic approach led to fewer falsepositive hits and therefore a more reliable screening process. 
A

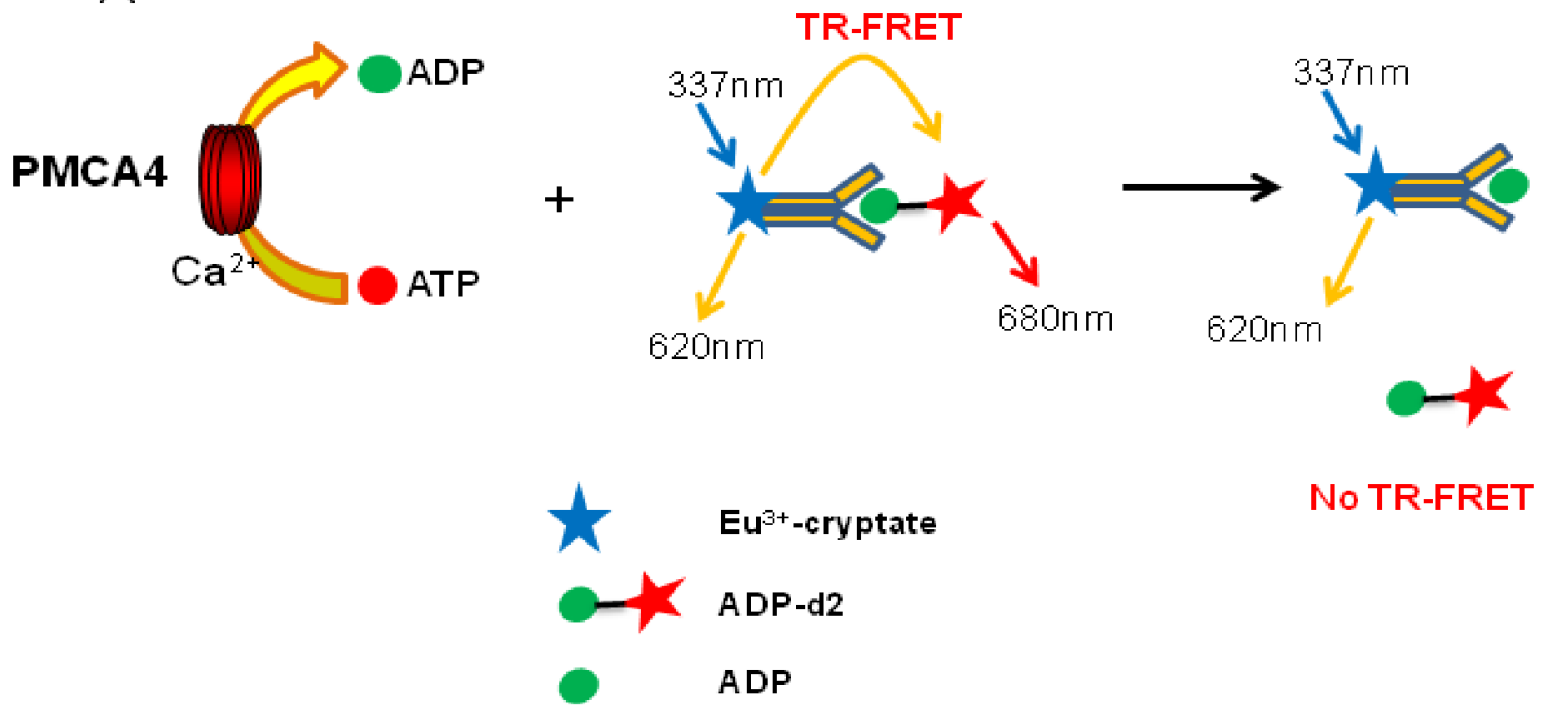

$\mathrm{B}$

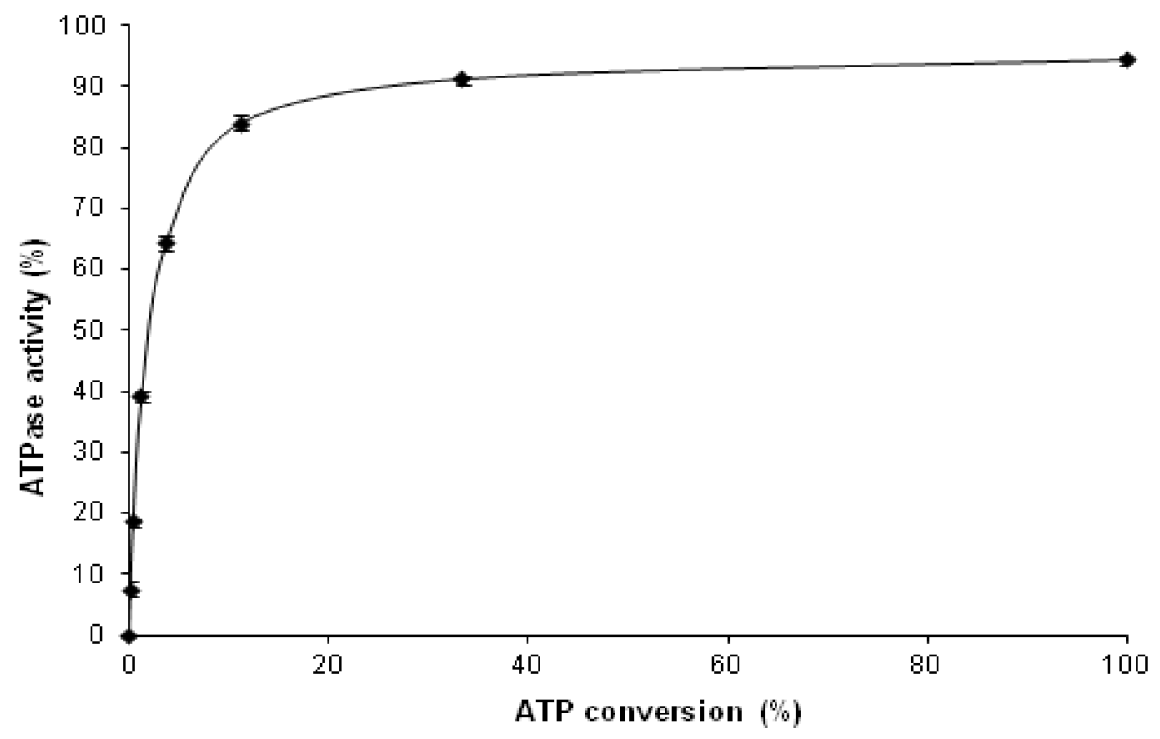

Figure 1. Homogeneous time resolved fluorescence assay (HTRF) assay principle and standard curve:

(A) Schematic diagram showing the assay principle for the HTRF ${ }^{\circledR}$ Transcreener ${ }^{\circledR}$ ADP assay (Cisbio). The detection method is based on an antibody specific to ADP which is labelled with $\mathrm{Eu}^{3+}$-cryptate, which is also able to bind to either (d2 acceptor dye)-coupled-ADP (to produce TR-FRET) or ADP released from the enzymatic ATPase reaction (no TR-FRET . The resulting TR-FRET signal is inversely proportional to the concentration of the non-labelled ADP in the sample. As PMCA4 is an ATPase pump that has the ability to convert ATP to ADP with the release of inorganic phosphate in a stoichiometric ratio, the released ADP due to ATP hydrolysis by PMCA4 would compete with ADP-d2 and reduce the TR-FRET signal. (B) Dose response for different ADP/ATP ratio which mimic an ATPase reaction (as ADP is produced, ATP is depleted). 


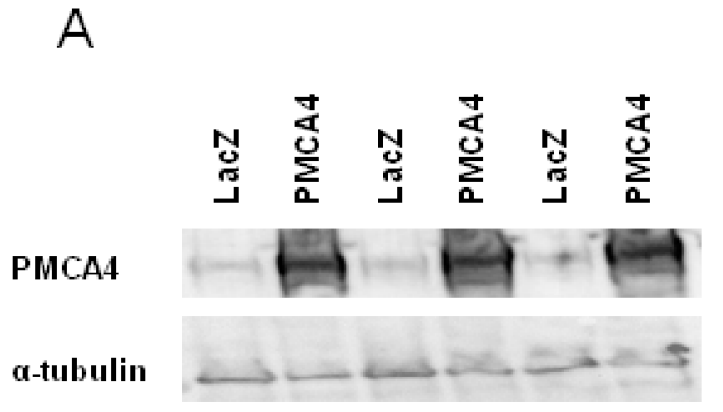

C
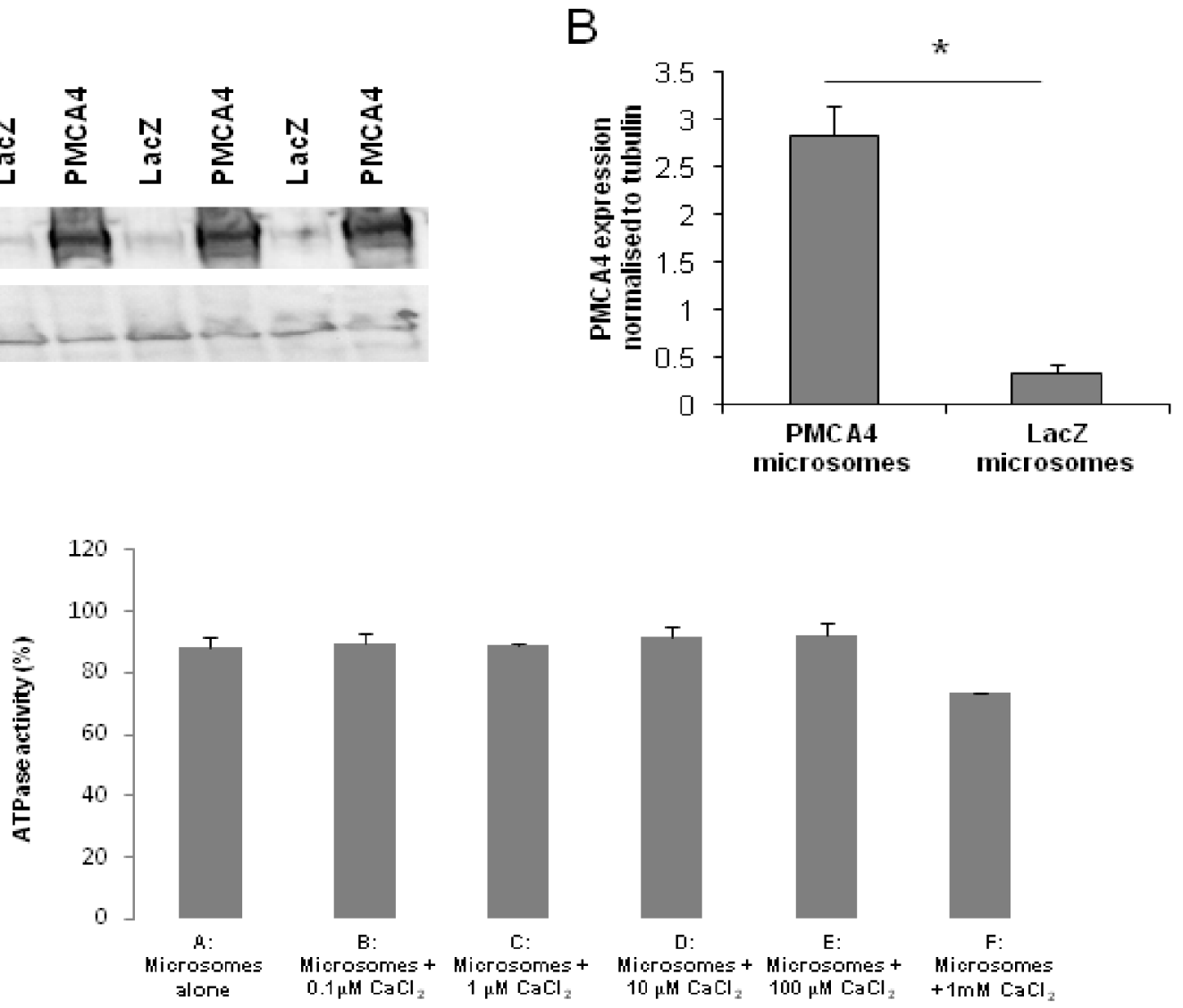
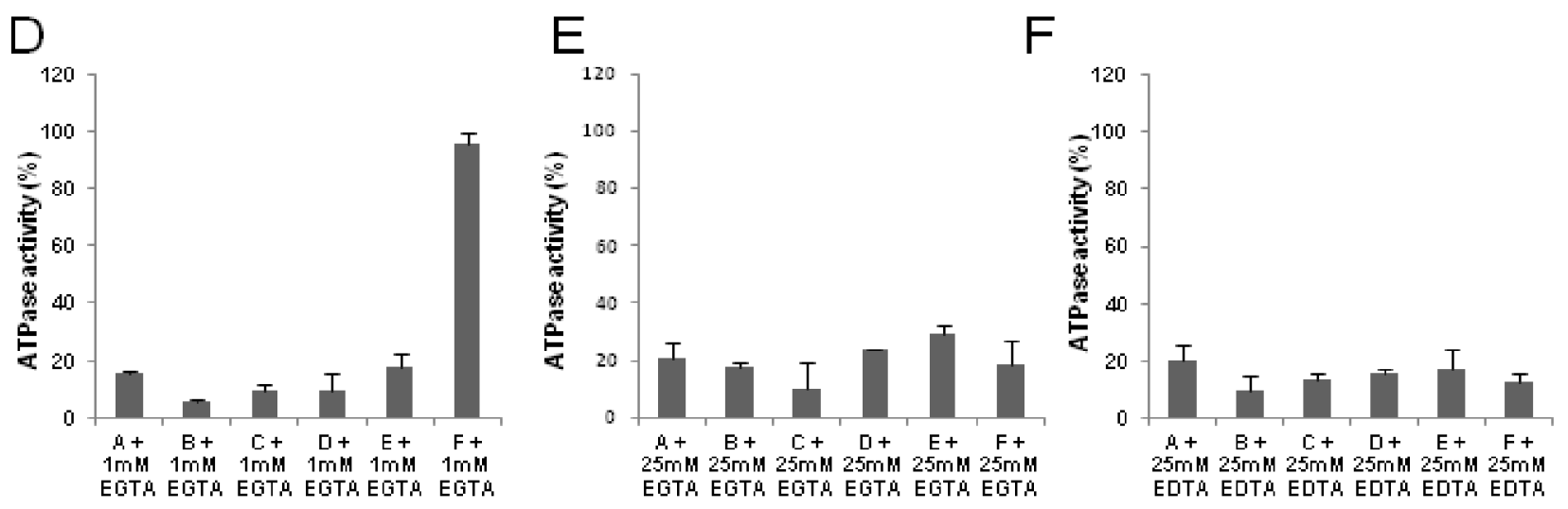

Figure 2. PMCA4 expression in microsomal preparations and optimisation of calcium buffering:

(A) Western blot analysis showing PMCA4 expression in PMCA4 microsomal membrane preparations against LacZ control microsomal preparations; $\alpha$-tubulin was used as a loading control. (B) Quantification of PMCA4 overexpression in PMCA4 and LacZ control microsomal preparations $(n=6, * p<0.05)$. Assessment of PMCA4 microsomes activity under various condition $(n=3$ independent experiments and each done in triplicate): (C) presence of different calcium concentrations; (D) after buffering calcium with 1mM EGTA; (E) full calcium depletion with $25 \mathrm{mM}$ EGTA ; (F) full calcium and magnesium depletion with $25 \mathrm{mM}$ EDTA. For all assays, ATPase activity $(\%)=$ $\left(1-\left(\mathrm{dF} / \mathrm{dF}_{\mathrm{max}}\right)\right) \times 100 . \mathrm{dF}=\left(\mathrm{F}_{\text {Sample }}-\mathrm{F}_{\mathrm{Blank}}\right) /\left(\mathrm{F}_{\text {Blank }}\right) \times 100$ and $\mathrm{dF}_{\max }=\mathrm{dF}$ of inactive microsomes which fully inhibited with $25 \mathrm{mM}$ EGTA. 


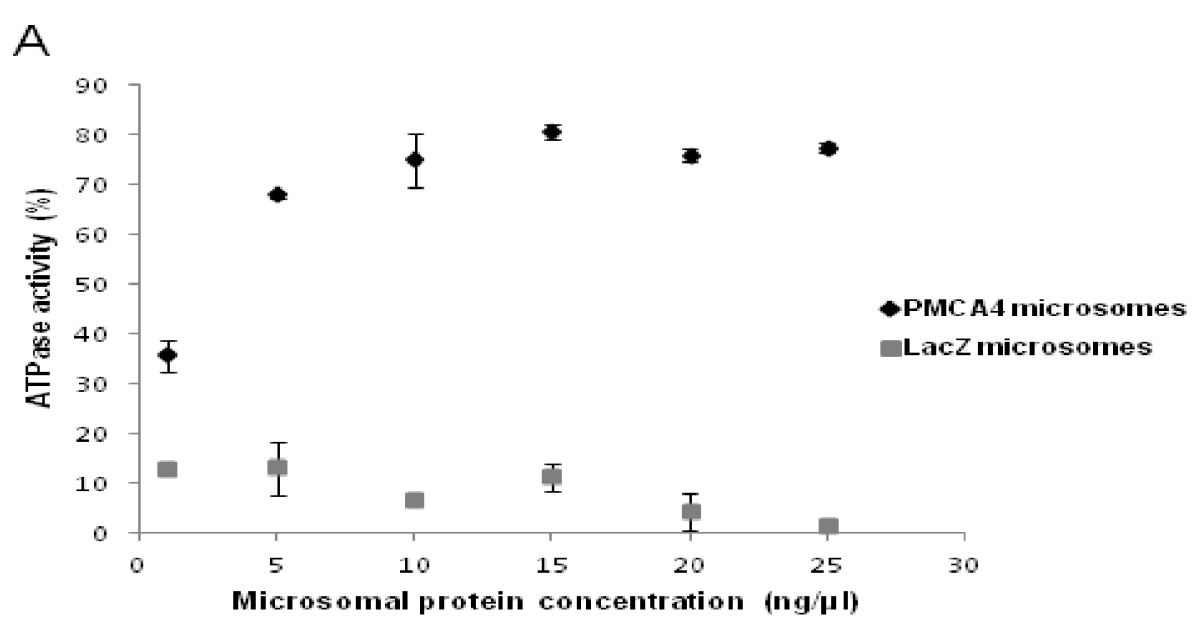

$\mathrm{B}$
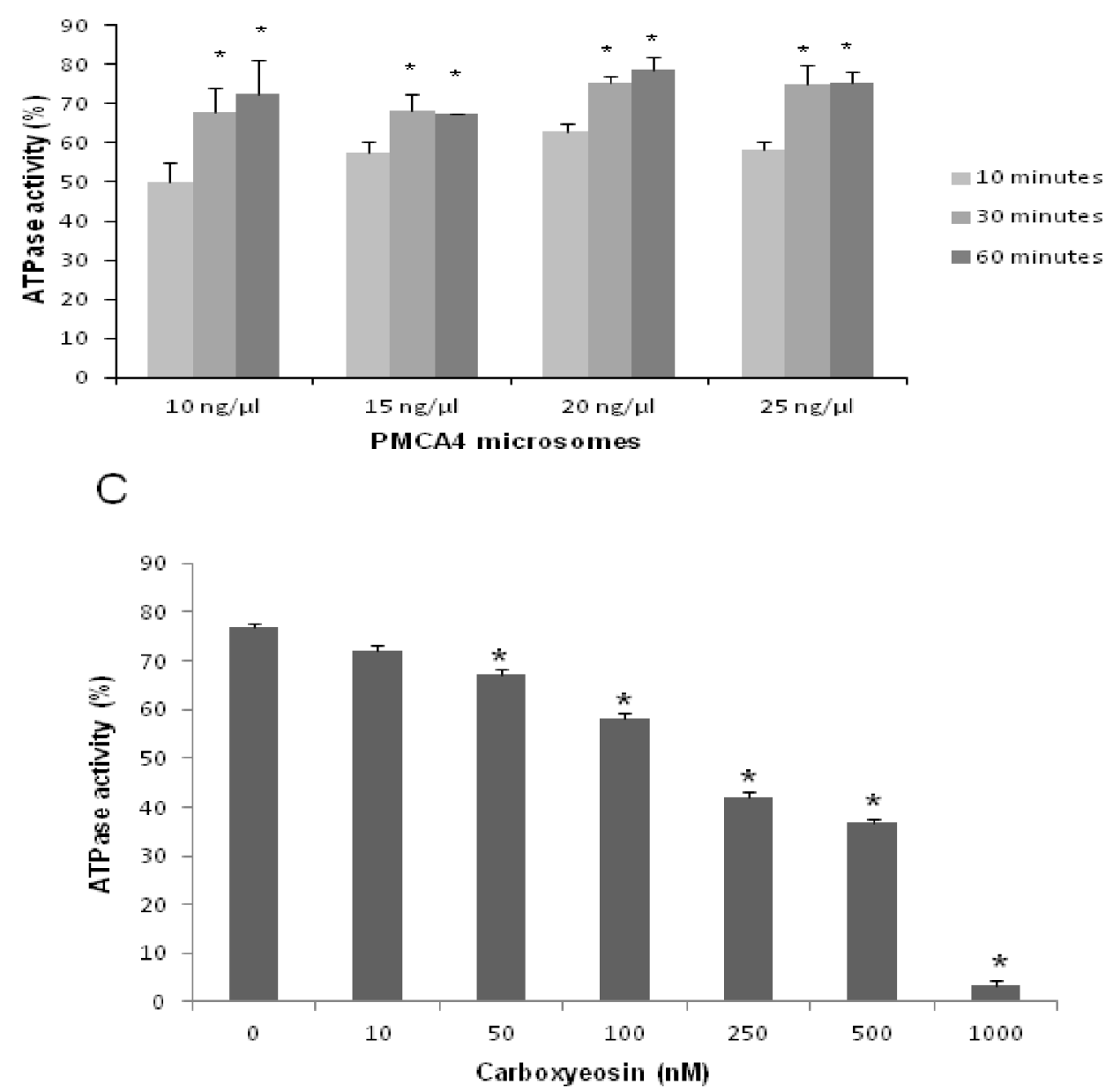

Figure 3. Optimisation of the assay conditions:

(A) Dose response curve for PMCA4 and LacZ control microsomes shows the activity of PMCA4 microsomes increased by increasing the amount of microsomes until reaching the maximal activity from $10 \mathrm{ng} / \mathrm{ul}$. However there is no considerable activity observed from the LacZ control microsomes $(n=3)$. (B) Assessment of various incubation times on PMCA4 micosomal preparations shows that the maximal activity was reached after 30 minutes incubation ( $\mathrm{n}=3,{ }^{*} \mathrm{p}<0.05$ vs 10 minutes). (C) Dose response curve for carboxyeosin (known PMCA non specific inhibitor) using the optimised conditions of microsomal amount (15ng) and incubation time (30 minutes) ( $\mathrm{n}=3,{ }^{*} \mathrm{p}<0.05$ vs no inhibitor). 
A
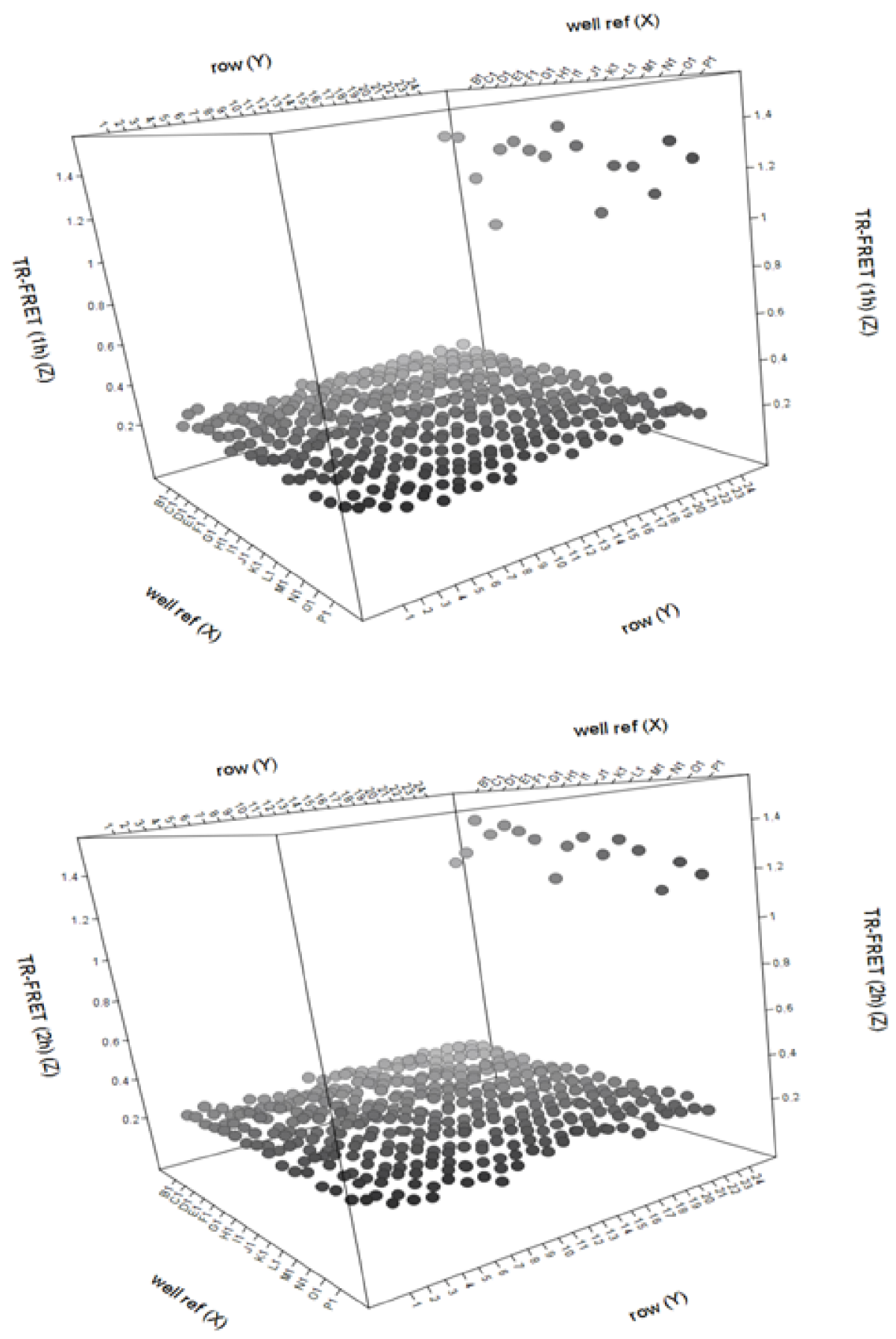
C

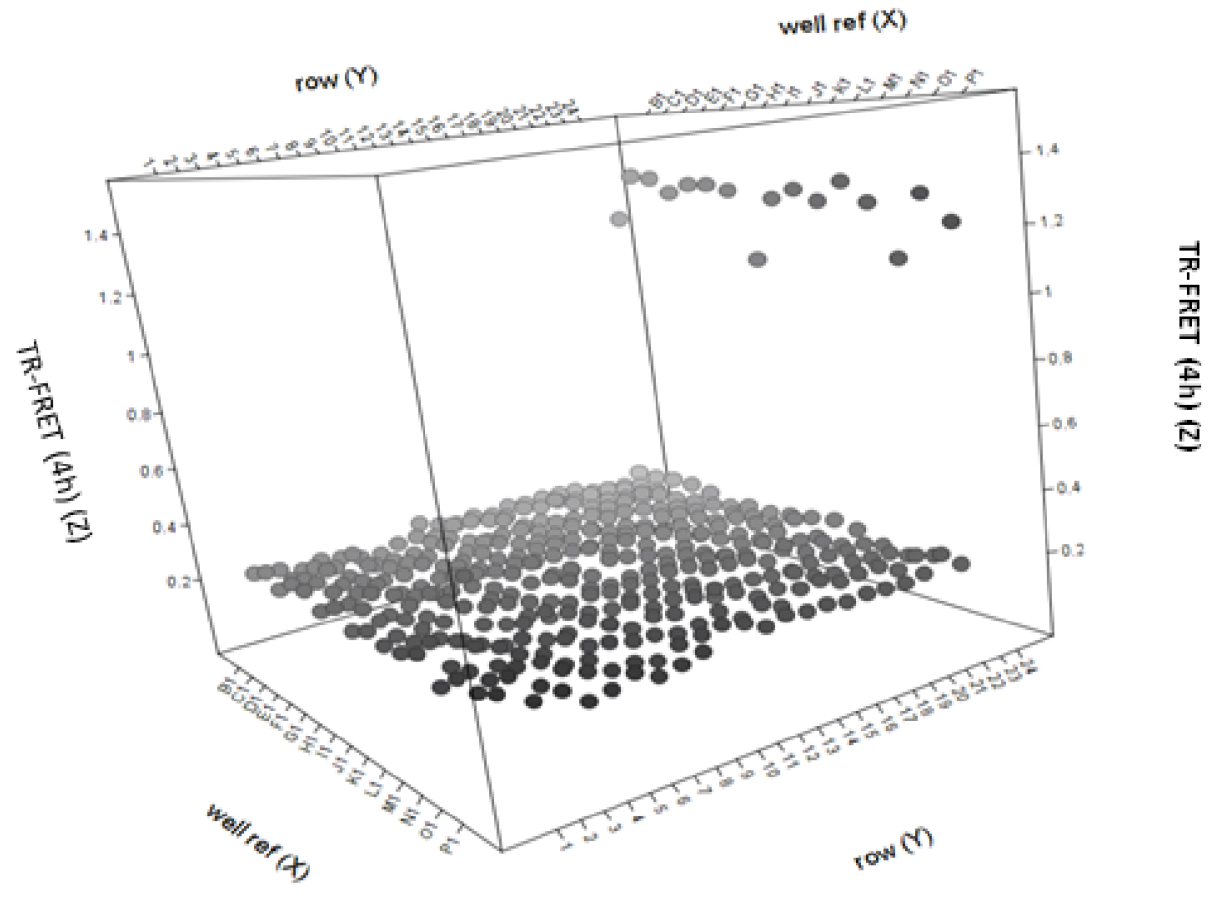

$\mathrm{D}$

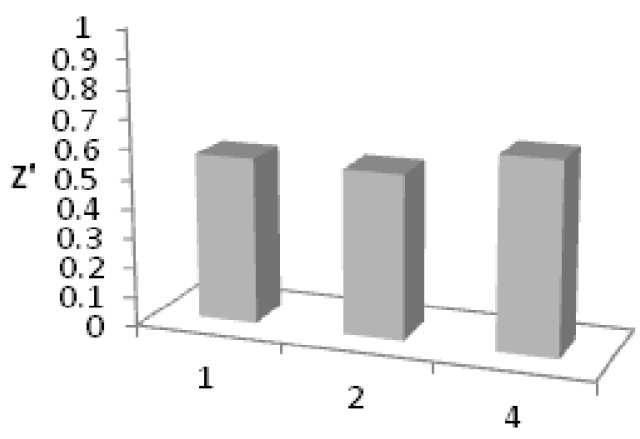

Time $(\mathrm{hr})$

Figure 4. Signal stability and Z:

Using the optimised conditions of microsome concentration and incubation times, DMSO plates were tested to check for edge effect, false positives and signal stability for 1 (A), 2 (B) and 4 (C) hours. Columns 1-23 contains 15ng microsomes and column 24 served as a negative control in which $1 \mu \mathrm{M}$ carboxyeosin was used to inhibit PMCA4. (D) $Z^{\prime}$ index for the reproducibility of the signal after 1,2 and 4 hours.

The discovery of specific pharmacological inhibitors/stimulators for PMCA isoforms, SERCA2 and other ATPases is now becoming more important due to their relevance in several human diseases as suggested by recent GWAS and several animal studies. Our studies in mice lacking PMCA4 [23] have also found male mice to be infertile due to a defect in sperm motility. In addition a more recent GWAS showed that the PMCA4 gene was associated with resistance to infection by malaria plasmodium in humans [25]. 


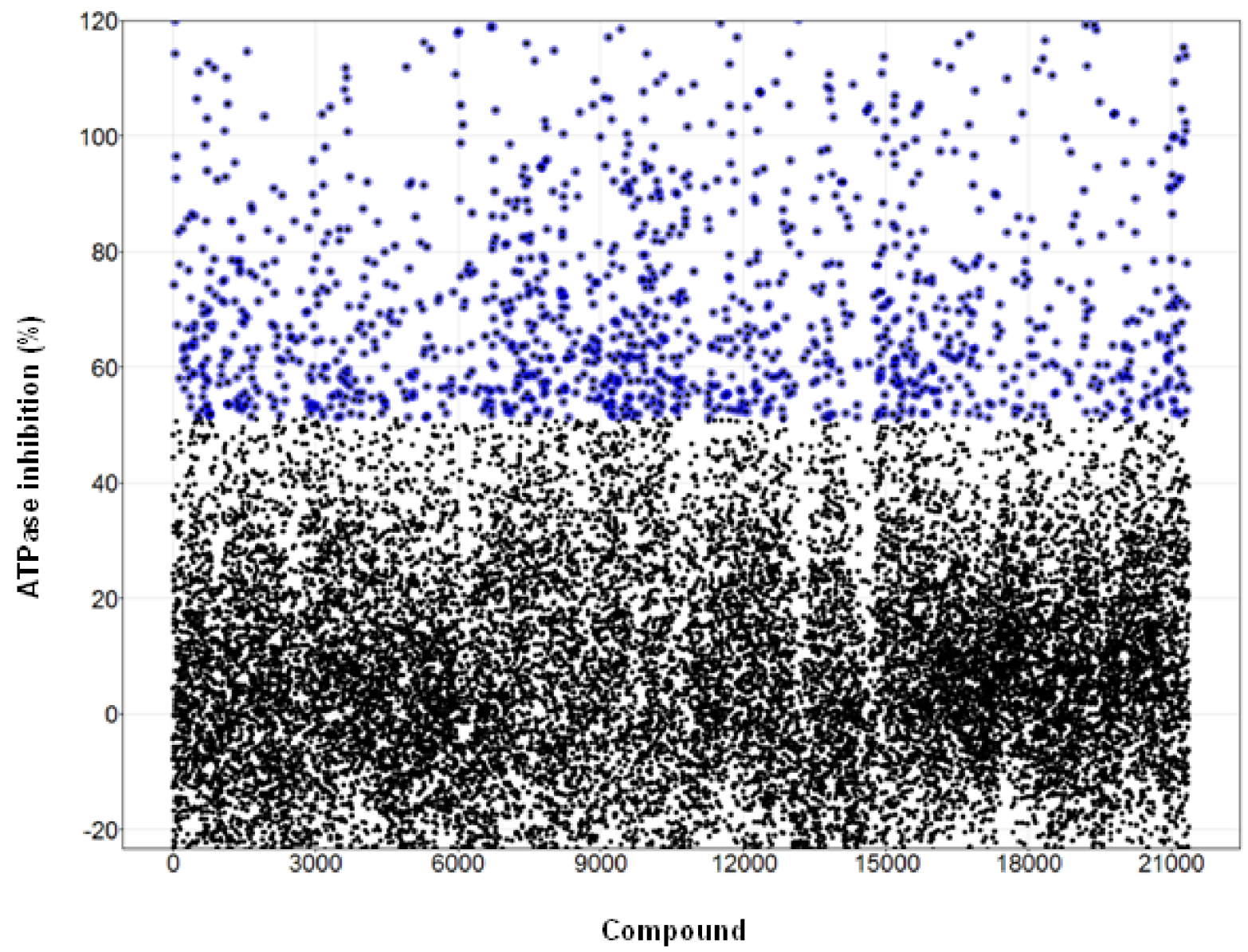

Figure 5. The output of the screen for PMCA4 against the ChemBioNet small molecule library.

Dot plot showing the inhibition (\%) of the screened compounds. Compounds with intensity in the Eu ${ }^{3+}$-cryptate channel $<70 \%$ and $>130 \%$ of DMSO controls were classified and removed as optical interfering compounds. The blue coloured dots correspond to 1,494 compounds that were identified as apparent inhibitors (yielding $>50 \%$ Inhibition) after excluding the optical interfering compounds.

Therefore, the discovery of a specific inhibitor for PMCA4 could have further potential applications in the fields of contraception and anti-malaria treatment. In addition, several GWAS have indicated the PMCA1 gene as being strongest associated with blood pressure (BP) in humans [12-15], PMCA2 was found to be associated with deafness [16-18] and mutations in PMCA3 found to be associated ataxia [22]. There are additional ATPases that have been implicated in pathological remodelling during heart failure, in particular, evidence has suggested the benefits of upregulating SERCA to treat and prevent heart failure $[5,7-9,38,39]$. Subsequent to Gwathmey et al. [38] documenting abnormal calcium homeostasis in myocardial specimens of endstage heart failure patients compared with controls, Mercadier et al. [5] attributed this to a relative decrease in SERCA mRNA levels using similar tissue specimens and this has fueled interest in therapeutically upregulating SERCA expression to restore calcium handling and consequently improve cardiac contractility/relaxation. Therefore, the discovery of a small molecule stimulator to SERCA will potentially improve heart failure.

It is currently estimated that the cost for successfully launching a new molecular entity is in the region of US $\$ 1,778$ million [40]. This is due in part to the increasing scrutiny of the drug safety and efficacy by regulatory bodies including the Food and Drug Administration with pharmaceutical companies under greater pressure to perform more expensive comparative trials of 
their new drugs against existing treatments [41]. Unsurprisingly, pharmaceutical companies are suffering a shortfall in profitability and productivity [40] which is exemplified by cardiovascular R\&D that was adversely affected when Pfizer withdrew cardiovascular research funding in 2008 [42]. Recently, there has been more focus on bench-to-bedside approaches, with genomic studies unveiling more promising therapeutic targets for novel therapies [43] offering potential to ATPases that are implicated in various diseases.

In summary, we have used PMCA4 as a model to optimise the $\mathrm{HTRF}^{\circledR}$ Transcreener $^{\circledR}$ ADP assay for a high throughput screening campaign to identify ATPase inhibitors and stimulators. By generating microsomes that overexpress PMCA4, validating PMCA4 overexpression by Western blot, and determining the optimal conditions to maximize baseline PMCA4 ATPase activity, we have described a screening assay to identify effective inhibitors of PMCA4. Further research is underway to explore whether the PMCA4 inhibitors exhibit suitable selectivity profiles with the ultimate aim to use them in animal models to assess their ability to treat malaria, or serve as a non-hormonal contraceptive. Utilising other mouse and human genome studies could also identify additional ATPase targets. Once such an ATPase target is identified, the HTRF $^{\circledR}$ Transcreener $^{\mathbb{B}}$ ADP assay (and associated microsomal system) can be used for high throughput screening of drug libraries to identify compounds for study in these additional disease indications, at least in suitable animal models. This translational research for discovering novel therapeutic targets is an essential step forward in drug development, and could potentially revolutionize pharmacological disease prevention and treatment.

\section{ACKNOWLEDGEMENTS}

This work was supported by the Medical Research Council (MRC) International Appointee Grant (G0200020), MRC Programme/Research Grants (G0500025, G0802004 and G1002082) to LN, and a British Heart Foundation (BHF) Project Grant (PG/05/082) to DO and EJC. DO is supported by a BHF Intermediate Basic Science Research Fellowship (FS/09/046). LN's laboratory is supported by the National Institute for Health Research, Manchester Biomedical Research Centre Funding Scheme. We would like to thank Terence Low and Jeanette Reinshagen for their help in preparing the figures.

\section{REFERENCES}

1. Sweadner KJ. Isozymes of the $\mathrm{Na}+/ \mathrm{K}+-\mathrm{ATPase}$. Biochim Biophys Acta. 1989;988:185-220.

2. Feraille E, Doucet A. Sodium-potassiumadenosinetriphosphatase-dependent sodium transport in the kidney: hormonal control. Physiol Rev. 2001;81:345-418.

3. Glynn IM. A hundred years of sodium pumping. Annu Rev Physiol. 2002;64:1-18.

4. Rabon EC, Reuben MA. The mechanism and structure of the gastric H,K-ATPase. Annu Rev Physiol. 1990;52:321-44.

5. Mercadier J, Lompre A, Duc P, Boheler K, Fraysse J, Wisnewsky C, et al. Altered sarcoplasmic reticulum $\mathrm{Ca} 2(+)$-ATPase gene expression in the human ventricle during endstage heart failure. The Journal of Clinical Investigation. 1990;85:305-9.

6. Overend CL, Eisner DA, O'Neill SC. Altered cardiac sarcoplasmic reticulum function of intact myocytes of rat ventricle during metabolic inhibition. Circulation Research. 2001;88:181-7.

7. Miyamoto MI, del Monte F, Schmidt U, DiSalvo TS, Kang ZB, Matsui T, et al. Adenoviral gene transfer of SERCA2a improves left-ventricular function in aortic-banded rats in transition to heart failure. Proceedings of the National Academy of Sciences. 2000;97:793-8.

8. Monte Fd, Harding SE, Schmidt U, Matsui T, Kang ZB, Dec GW, et al. Restoration of contractile function in isolated cardiomyocytes from failing human hearts by gene transfer of SERCA2a. Circulation. 1999;100:2308-11.

9. Monte Fd, Williams E, Lebeche D, Schmidt U, Rosenzweig A, Gwathmey JK, et al. Improvement in survival and cardiac metabolism after gene transfer of sarcoplasmic reticulum Ca2+-ATPase in a rat model of heart failure. Circulation. 2001;104:1424-9.

10. Oceandy D, Stanley P, Cartwright E, Neyses L. The regulatory function of plasma-membrane $\mathrm{Ca}$ (2+)-ATPase (PMCA) in the heart. Biochemical Society Transactions. 2007;35:927-30.

11. Cartwright EJ, Oceandy D, Austin C, Neyses L. $\mathrm{Ca} 2+$ signalling in cardiovascular disease: the role of the plasma membrane calcium pumps. Science China Life Sciences. 2011;54:691-8.

12. Cho YS, Go MJ, Kim YJ, Heo JY, Oh JH, Ban HJ, et al. A large-scale genome-wide association study of Asian populations uncovers genetic factors influencing eight quantitative traits. Nat Genet. 2009;41:527-34.

13. Levy D, Ehret GB, Rice K, Verwoert GC, Launer LJ, Dehghan A, et al. Genome-wide association study of blood pressure and hypertension. Nat Genet. 2009;41:677-87. 
14. Kobayashi Y, Hirawa N, Tabara Y, Muraoka H, Fujita M, Miyazaki N, et al. Mice lacking hypertension candidate gene ATP2B1 in vascular smooth muscle cells show significant blood pressure elevation. Hypertension. 2012;59:854-60.

15. Tabara Y, Kohara K, Kita Y, Hirawa N, Katsuya $\mathrm{T}$, Ohkubo $\mathrm{T}$, et al. Common variants in the ATP2B1 gene are associated with susceptibility to hypertension: the Japanese Millennium Genome Project. Hypertension. 2010;56:973-80.

16. Street VA, McKee-Johnson JW, Fonseca RC, Tempel BL, Noben-Trauth K. Mutations in a plasma membrane $\mathrm{Ca} 2+-\mathrm{ATPase}$ gene cause deafness in deafwaddler mice. Nature Genetics. 1998;19:390-4.

17. Schultz JM, Yang Y, Caride AJ, Filoteo AG, Penheiter AR, Lagziel A, et al. Modification of human hearing loss by plasma-membrane calcium pump PMCA2. New England Journal of Medicine. 2005;352:1557-64.

18. Kozel PJ, Friedman RA, Erway LC, Yamoah EN, Liu LH, Riddle $\mathrm{T}$, et al. Balance and hearing deficits in mice with a null mutation in the gene encoding plasma membrane $\mathrm{Ca} 2+-\mathrm{ATPase}$ isoform 2. Journal of Biological Chemistry. 1998;273:18693-6.

19. Greeb J, Shull GE. Molecular cloning of a third isoform of the calmodulin-sensitive plasma membrane $\mathrm{Ca} 2+$-transporting ATPase that is expressed predominantly in brain and skeletal muscle. Journal of Biological Chemistry. 1989;264:18569-76.

20. Stauffer TP, Guerini D, Carafoli E. Tissue distribution of the four gene products of the plasma membrane Ca pump. Journal of Biological Chemistry. 1995;270:12184-90.

21. Kamagate A, Herchuelz A, Bollen A, Eylen FV. Expression of multiple plasma membrane $\mathrm{Ca} 2+$ ATPases in rat pancreatic islet cells. Cell Calcium. 2000;27:231-46.

22. Zanni G, Cali T, Kalscheuer VM, Ottolini D, Barresi S, Lebrun $\mathrm{N}$, et al. Mutation of plasma membrane $\mathrm{Ca} 2+$ ATPase isoform 3 in a family with X-linked congenital cerebellar ataxia impairs $\mathrm{Ca} 2+$ homeostasis. Proc Natl Acad Sci U S A. 2012;109:14514-9.

23. Schuh K, Cartwright EJ, Jankevics E, Bundschu $\mathrm{K}$, Liebermann J, Williams JC, et al. Plasma membrane $\mathrm{Ca} 2+$ ATPase 4 is required for sperm motility and male fertility. J Biol Chem. 2004;279:28220-6.

24. Okunade GW, Miller ML, Pyne GJ, Sutliff RL, O'Connor KT, Neumann JC, et al. Targeted ablation of plasma membrane $\mathrm{Ca} 2+$-ATPase (PMCA) 1 and 4 indicates a major housekeeping function for PMCA1 and a critical role in hyperactivated sperm motility and male fertility for PMCA4. J Biol Chem. 2004;279:33742-50.

25. Timmann C, Thye T, Vens M, Evans J, May J, Ehmen $\mathrm{C}$, et al. Genome-wide association study indicates two novel resistance loci for severe malaria. Nature. 2012;489:443-6.

26. Mohamed T, Baudoin-Stanley FM, Abou-Leisa R, Cartwright E, Neyses L, Oceandy D. Measurement of plasma membrane calcium-calmodulindependent ATPase (PMCA) activity. Methods in Molecular Biology (Clifton, NJ). 2010;637:33342.

27. Fabiato online tool. http://maxchelator.stanford.edu/downloads.htm

28. Fabiato A. [31] Computer programs for calculating total from specified free or free from specified total ionic concentrations in aqueous solutions containing multiple metals and ligands. In: Sidney Fleischer BF, editor. Methods in Enzymology: Academic Press; 1988. p. 378-417.

29. Gatto C, Milanick MA. Inhibition of the red blood cell calcium pump by eosin and other fluorescein analogues. American Journal of Physiology - Cell Physiology. 1993;264:C1577-C86.

30. Gatto C, Hale CC, Xu W, Milanick MA. Eosin, a potent inhibitor of the plasma membrane $\mathrm{Ca}$ pump, does not inhibit the cardiac $\mathrm{Na}-\mathrm{Ca}$ exchanger. Biochemistry. 1995;34:965-72.

31. Choi HS, Eisner DA. The role of sarcolemmal $\mathrm{Ca} 2+-\mathrm{ATPase}$ in the regulation of resting calcium concentration in rat ventricular myocytes. The Journal of Physiology. 1999;515 ( Pt 1):109-18.

32. Jones J, Rodgers J, Heil M, May J, White L, Maddry JA, et al. High throughput drug screening for human immunodeficiency virus type 1 reactivating compounds. Assay Drug Dev Technol. 2007;5:181-89.

33. Jeffery JA, Sharom JR, Fazekas M, Rudd P, Welchner E, Thauvette L, et al. An ATPase assay using scintillation proximity beads for highthroughput screening or kinetic analysis. Analytical Biochemistry. 2002;304:55-62.

34. Avila C, Hadden MK, Ma Z, Kornilayev BA, Ye Q-Z, Blagg BSJ. High-throughput screening for Hsp90 ATPase inhibitors. Bioorganic \& Medicinal Chemistry Letters. 2006; 16:3005-8.

35. Rowlands MG, Newbatt YM, Prodromou C, Pearl LH, Workman P, Aherne W. High-throughput screening assay for inhibitors of heat-shock protein 90 ATPase activity. Analytical Biochemistry. 2004;327:176-83.

36. Osborn KD, Zaidi A, Mandal A, Urbauer RJ, Johnson CK. Single-molecule dynamics of the calcium-dependent activation of plasmamembrane $\mathrm{Ca} 2+-\mathrm{ATPase}$ by calmodulin. Biophys J. 2004;87:1892-9.

37. Mohamed TM, Baudoin-Stanley FM, Abou-Leisa R, Cartwright E, Neyses L, Oceandy D. Measurement of plasma membrane calciumcalmodulin-dependent ATPase (PMCA) activity. Methods in molecular biology (Clifton, NJ. 2010;637:333-42.

38. Gwathmey JK, Copelas L, MacKinnon R, Schoen FJ, Feldman MD, Grossman W, et al. Abnormal intracellular calcium handling in myocardium 
from patients with end-stage heart failure. Circulation Research. 1987;61:70-6.

39. Jaski BE, Jessup ML, Mancini DM, Cappola TP, Pauly DF, Greenberg B, et al. Calcium upregulation by percutaneous administration of gene therapy in cardiac disease (CUPID trial), a first-in-human phase 1/2 clinical trial. Journal of Cardiac Failure. 2009;15:171-81.

40. Paul SM, Mytelka DS, Dunwiddie CT, Persinger $\mathrm{CC}$, Munos $\mathrm{BH}$, Lindborg $\mathrm{SR}$, et al. How to improve R\&D productivity: the pharmaceutical industry's grand challenge. Nature Reviews Drug Discovery. 2010;9:203-14.

41. Garber AM. An uncertain future for cardiovascular drug development? New England Journal of Medicine. 2009;360:1169-71.

42. Wang S, Lublin J. Pfizer plans to abandon heartdrug development. Wall Street Journal. 2008.

43. Plump AS, Lum PY. Genomics and cardiovascular drug development. Journal of the American College of Cardiology. 2009;53:1089-100. 